\title{
Budget Impact Analysis Of Subcutaneous Belimumab In Patients With Systemic Lupus Erythematosus In
} Spain

This article was published in the following Dove Press journal: ClinicoEconomics and Outcomes Research

\author{
Maria Cevey (D) $^{\prime}$ \\ Jaime Calvo-Alén (iD ${ }^{2}$ \\ Carlos Crespo $\mathbb{1 D}^{3}$ \\ Angel Robles- \\ Marhuenda (D) ${ }^{4}$ \\ Lee Smolen (iD $)^{5}$ \\ Josefina Cortés-Hernández 6 \\ 'Department of Market Access, \\ GlaxoSmithKline SA, Madrid, Spain; \\ ${ }^{2}$ Department of Rheumatology, University \\ Hospital Araba, Vitoria, Spain; \\ ${ }^{3}$ Department of Genetics, Microbiology \\ and Statistics, Statistics Section, University \\ of Barcelona, Barcelona, Spain; \\ ${ }^{4}$ Department of Internal Medicine, Hospital \\ La Paz, Madrid, Spain; ${ }^{5}$ Modeling \& \\ Analytics, Medical Decision Modeling Inc, \\ Indianapolis, IN, USA; ${ }^{6}$ Department of \\ Internal Medicine, Vall d'Hebron Institut de \\ Recerca (VHIR), Barcelona, Spain
}

Correspondence: Josefina CortésHernández

Department of Internal Medicine, Vall d'Hebron Institut de Recerca (VHIR), Vall d'Hebron University Hospital Research Institute, Passeig Vall d'Hebron I19-129, Barcelona 08035, Spain

Tel +34934893000

Fax +34934894438

Email fina.cortes@vhir.org
Objective: To evaluate the budget impact and the direct costs of the introduction of subcutaneous belimumab (SC) into the Spanish National Health Service (NHS) for patients with systemic lupus erythematosus (SLE) in Spain.

Methods: This study was conducted from the Spanish NHS perspective with a time horizon of 3 years. The budget impact analysis compared the cost difference between two scenarios: current market (standard therapy (ST) and intravenous belimumab (IV)) and other market in which patients switched from belimumab IV to belimumab SC until reaching $17 \%$ of the total market share. The eligible population was calculated to receive treatment with belimumab, applying the EPISER (study of the prevalence of rheumatic diseases in adult population in Spain) prevalence (91 per 100,000 inhabitants), Autoimmune Systemic Diseases Study Group (GEAS) incidence ( 2 per 100,000 inhabitants), and the risk of annual mortality to the Spanish adult population. Patients with severe active lupus nephritis and with severe active CNS lupus were excluded. Patients' characteristics, flare rates and severity, and healthcare resource consumption were evaluated based on data from the literature and interviews with an expert panel. A sensitivity analysis was performed.

Results: Currently, there is an estimated 34,697 adult patients with SLE in Spain and 3849 patients who are eligible to be treated with belimumab. The introduction of belimumab SC into the Spanish NHS could generate savings in direct healthcare costs of 6 million euros over the 3 years.

Conclusion: The introduction of belimumab SC shows direct savings for the Spanish NHS. These savings could contribute to sustainability and decision-making.

Keywords: belimumab, budget impact, Spanish National Health Service, NHS, Systemic Lupus Erythematosus

\section{Introduction}

Systemic lupus erythematosus (SLE) is a severe autoimmune disease which can affect multiple organs ${ }^{1}$ and which presents different clinical manifestations. ${ }^{2}$ It can affect any organ or system, with joints, kidneys, and the skin the most commonly affected areas. ${ }^{3}$

Most patients have a relapsing and remitting clinical course in the form of flares or exacerbations interspersed with periods of inactivity. These flares can lead mainly to irreversible alterations of vital organs, ${ }^{1}$ which may affect the survival rate of patients with SLE. $^{2}$ Likewise, SLE negatively impacts patient quality of life. ${ }^{4}$

The complexity of this disease and the time it takes before the appearance of severe symptoms make it difficult to make an early diagnosis in patients with SLE. ${ }^{5}$ 
A study carried out in Germany showed that it is possible to reduce the time until the first rheumatology appointment by making doctors and the health system aware of the seriousness of this disease. This would result in better management of the patient and disease activity, as well as a reduction in the healthcare resources and benefit patients to continue to work. ${ }^{5}$ Early diagnosis, disease control, and adjustment of therapies according to the treat to target concept are important in avoiding severe flares and irreversible organ damage and can maintain the patient in a state of remission or low disease activity. ${ }^{6}$ The SLE clinical practice guidelines from the Ministry of Health, Social Services and Equality, ${ }^{1}$ the Spanish Society of Rheumatology (SER), ${ }^{7}$ and the Spanish Society of Internal Medicine (SEMI) ${ }^{8}$ agree that the main objective of the drug therapy for patients with SLE is to avoid flares of disease in order to prevent irreversible organ damage.

The Systemic LUpus Erythematosus Cost of Care In Europe Study (LUCIE) on the burden of SLE illness carried out in 5 European countries, including Spain, concluded that inadequate management of SLE activity produces an increase in severe flares; this entails an increase in the associated costs, mainly in hospital admissions. ${ }^{9}$ In the retrospective study reviewing medical records across 5 hospitals in Spain, the healthcare resources associated with the managing and treating SLE and its flares, and the associated direct cost, were studied from a Spanish NHS perspective. We included adult patients with SLE (ACR criteria) with positive autoantibodies, receiving medical treatment and with active disease. The patients were classified into severe and not severe. Severe patients were defined as having at least one major domain involved at inclusion (renal, neurological, cardiovascular, or respiratory) and requiring prednisone equivalent dosages $>7.5$ $\mathrm{mg} /$ day and/or immunosuppressants. Patients' disease activity and severity were assessed at baseline. In this study, only direct costs were included: laboratory and diagnostic tests, drug therapies, specialist visits, and hospital admissions. Despite treatment, management of disease activity was inadequate in the majority of patients, with $90.7 \%$ presenting at least one flare during a two-year follow-up period. The major component of the healthcare cost related to hospital admissions, which constituted $44.8 \%$ of the total cost. It was found that the average annual direct cost associated with the management of SLE was $€ 4833$ per patient. The cost associated with the treatment and management of patients with severe disease
$(€ 5968)$ was significantly higher than that of non-severe patients $(€ 3604)(p=0.003) .{ }^{10}$ This cost may have been higher if the social perspective had been taken into account in the study. A study showed that $36 \%$ of the employed patients with SLE and $40 \%$ of those with rheumatoid arthritis had had at least one period of sick leave during the past 12 months. ${ }^{11}$

The budget impact has become a significant pharmacoeconomic element in decision-making. It allows us to estimate the financial viability of introducing new technologies, providing very useful information for healthcare decision-makers. ${ }^{12}$ The objective of this study was to estimate the budget impact of incorporating belimumab SC within the Spanish National Health Service (NHS) as an adjuvant treatment for SLE in adult patients with positive autoantibodies and high disease activity in Spain. Patients with severe active lupus nephritis or severe active Central Nervous System (CNS) lupus were excluded.

\section{Materials And Methods}

A budget impact model was developed from the perspective of the Spanish NHS. Direct health costs: pharmacological treatments, administration, and management of flares were evaluated. The costs were estimated for a time horizon of 3 years (2018 to 2020) without applying a discount rate, as indicated in the international guidelines. ${ }^{11}$ Indirect costs were not included.

The model was completed with data from published literature, official publications, market research data, and through a questionnaire conducted with a panel of experts comprising specialists in Rheumatology and Internal Medicine, which addressed those assumptions where data were not available. In addition, the panel of experts also validated the data used. This study was funded by GlaxoSmithKline and the panel of experts were not blinded about the study.

The budget impact model compared the cost difference in each year in two scenarios: a current market scenario: standard therapy and belimumab IV without belimumab $\mathrm{SC}$; and a new market scenario: in which the patients switched from belimumab IV to belimumab SC until reaching approximately $17 \%$ of the market share. The assumption of the proportion of patients in both scenarios according to their distribution in the different drug therapies over the 3-year horizon was made taking into account the company's internal data, market research, and assessment by the expert panel. The following distribution of patients was assumed as a percentage in the different scenarios: 
- Current scenario: belimumab IV + standard therapy ( $22.8 \%$ in year $1,23.7 \%$ in year $2,23.2 \%$ in year 3 ) and standard therapy $(77.2 \%$ in year $1,76.3 \%$ in the year $2,76.8 \%$ in year 3 ).

- New scenario: belimumab SC + standard therapy ( $7.5 \%$ in year $1,14.5 \%$ in year $2,16.8 \%$ in year 3 ); belimumab IV + standard therapy $(15.3 \%$ in year 1 , $9.2 \%$ in year $2,6.4 \%$ in year 3 ) and standard therapy $(77.2 \%$ in year $1,76.3 \%$ in year $2,76.8 \%$ in year 3$)$.

\section{Population Eligible For Treatment With Belimumab}

The estimated eligible population to receive belimumab treatment was calculated from the general population of adults in Spain ( $\geq 18$ years), according to data from the National Institute of Statistics. ${ }^{13}$ Epidemiological data on the prevalence of SLE from the EPISER epidemiological study (91 per 100,000 inhabitants) were applied, ${ }^{14}$ of which $88 \%$ of the cases are diagnosed. ${ }^{15}$ Based on the study by Somers et $\mathrm{al}^{16}$ and the Spanish study by Rúa-Figueroa et $\mathrm{al}^{17}$ $32 \%$ of the SLE population was excluded due to suffering from severe active lupus nephritis or severe active Central Nervous System (CNS) lupus, as set out in Summary Product of Characteristics. ${ }^{18}$ Likewise, only $59 \%$ of the population had positive autoantibody tests ( $99 \%$ based on ANA) and active disease. ${ }^{19}$ Finally, we identified the subgroup of patients with high disease activity despite standard therapy $(35 \%)^{9}$ and who are on pharmacological treatment $(90 \%) .{ }^{14}$

In order to estimate the direct cost offsets related to belimumab SC, a pharmacoeconomic study was conducted. This model was developed in Excel 2010 and complies with the International Society for Pharmacoeconomics and Outcomes Research (ISPOR) ${ }^{12}$ best practice guidelines.

In the model, the annual incidence of SLE ( 2 per 100,000 population-year) from the GEAS group ${ }^{20}$ and the adjusted Spanish mortality ${ }^{21}$ for patients with SLE were taken into account. In order to estimate the mortality, the SLE specific mortality risk from Bultink ${ }^{22}$ for patients under 40 years (RR: 4.87) and from the Bernatsky study ${ }^{23}$ for the other patients (between 40 and 59 years RR: 3.5 and for 60 years or more RR: 1.5) was applied to the all-cause mortality risk in Spain. The age distribution of the Spanish Rheumatology Society SLE Registry (RELESSER-T) study was used. ${ }^{24}$ The risk of annual mortality of patients with SLE for Spain is $0.129 \%$ for patients $<40$ years, $0.635 \%$ for patients of $40-59$ years, and $5.484 \%$ for patients of $\geq 60$ years.
The pharmacoeconomic model assumed that in the first year the prevalence includes the mortality and the new cases of the first 6 months. For this reason, the incidence of the first year would be half that of subsequent years.

\section{Treatments And Costs}

Annual treatment costs of different pharmacological treatments were calculated using the ex-factory price. ${ }^{25}$

According to Summary Product of Characteristics, the recommended dose of belimumab IV is $10 \mathrm{mg} / \mathrm{kg}$ on days 0 , 14 , and 28 , and then at 4-week intervals. ${ }^{26}$ Therefore, in the first year, the patient receives 15 administrations and from the second year receives 13 administrations. As Benlysta IV depends on weight, the average weight $(69 \mathrm{~kg})$ of the Study of Belimumab Subcutaneous in Subjects with SLE trial [BLISS-SC] was used as a reference for calculating annual treatment cost. $^{27}$

According to Summary Product of Characteristics, the recommended dose of belimumab SC is $200 \mathrm{mg}$ once a week, administered subcutaneously and the dosage is not based on weight. ${ }^{28}$ We estimate 52 administrations per year.

The standard therapy, according to the Clinical Practice Guidelines from the Ministry of Health, Social Services and Equality $^{1}$ and the distribution allocated by the panel of experts, encompassed $83 \%$ corticosteroids, $83 \%$ anti-malarials, 52\% non-biological immunosuppressants (non-biological immunosuppressants: methotrexate, intravenous cyclophosphamide, leflunomide, azathioprine, cyclosporine, and mycophenolate), $20 \%$ NSAIDs, $13 \%$ other biologic immunosuppressants used off-label such as rituximab, $2 \%$ intravenous immunoglobulins, and $0.07 \%$ plasmapheresis. Drug cost price was based on ex-factory price. ${ }^{25}$ Taking into account, the weight of SLE patients $(69 \mathrm{~kg})^{26}$ and the body surface area $\left(1.8 \mathrm{~m}^{2}\right),{ }^{29}$ in necessary cases, and the rate of plasma exchange, ${ }^{30-32}$ the average annual treatment cost calculated of standard therapy was $€ 1034.71$. Doses of different pharmacological treatments were validated by the expert panel. In the case of standard therapy administered with belimumab SC and IV, the average annual treatment cost calculated of standard therapy was $€ 438.42$, because it did not include other biologic treatments.

\section{Estimated Cost Of Administration}

The cost of administration of intravenous treatments was calculated using administration hospital fees (€260.67). ${ }^{32-40}$

The average cost calculated for standard therapy administration was $€ 205.62$ per patient. However, the average cost of standard therapy administration when it 
was administered together with belimumab SC and IV was $€ 103.96$ per patient, because it did not include other biologic treatments.

\section{Estimated Costs Of Managing Severe And Non-Severe Flares}

The number of flares per treatment was estimated based on changes in the SELENA-SLEDAI score, changes in the signs or symptoms of disease activity, changes in prednisone dose, use of new drugs due to disease activity, and changes in the physician's global assessment (PGA). Nonsevere flares were defined as flares triggered by an increase of $\geq 3$ in the SELENA-SLEDAI score. Serious flares were defined as flares triggered by an increase of $>12$ in SELENA-SLEDAI score or a flare requiring hospital admission. Considering that the efficacy of belimumab SC and IV is equivalent, ${ }^{41}$ the same number of severe and non-severe flares was used for both formulations of belimumab. Adding belimumab to standard therapy showed an average of 2.15 non-severe flares per year, while standard therapy alone showed an annual average of 2.5 non-severe flares. Likewise, adding belimumab to standard therapy showed an annual average of 0.54 severe flares compared to 1.01 with standard therapy alone. ${ }^{42}$

To calculate the cost of management severe flares, the average cost of hospital admission for connective tissue disorder with complications was assumed at $€ 4840.29$ / event. ${ }^{43}$ This cost was based on DRG (Diagnosis Related Groups) 240: Connective tissue disorders with complications that group patients according to admission for a connective tissue disease such as SLE, rheumatoid arthritis, amyloidosis, juvenile rheumatoid arthritis, etc. To calculate the cost of management non-severe flares was assumed: a visit to the specialist (€92.54), a laboratory test $(€ 68.32)^{43-49,50}$ and that $10 \%$ of the patients required hospital admission, applied to the average cost of DRG 241: Connective tissue disorders without complications (€386.26/event). ${ }^{42}$ This means the cost of treating a nonsevere flare was $€ 547.12$.

\section{Sensitivity Analysis}

Taking into account that economic models have a certain level of uncertainty associated with the assumptions made, in this budget impact analysis a sensitivity analysis was carried out using a tornado diagram to assess the robustness of the results. The various assumptions were the percentage of patients with high disease activity, the percentage of patients with positive autoantibodies and active disease, the percentage of patients without severe active lupus nephritis or severe active CNS lupus, the percentage of patients treated, weight, the percentage of patients diagnosed, the percentage of patients according to age, and relative risk of mortality. These assumptions were validated and agreed with the panel of experts.

\section{Results}

It is currently estimated that there are 34,697 adult patients with SLE, $88 \%(30,533)$ of whom have been diagnosed. A total of 20,610 of these are patients without severe active lupus nephritis or severe active CNS lupus, decreasing to around 3849 patients with positive autoantibodies and high disease activity on pharmacological treatment (Table 1). The 3-year projection for this subgroup of patients with SLE with positive autoantibodies and high disease activity is 3891 patients in the first year, 3943 in the second year, and 3995 in the third year, assuming an average annual incidence of 85 patients and an annual mortality of 33 patients.

\section{Direct Costs}

The annual cost of treatment with belimumab SC was $€ 11,902.80$ per patient. The annual cost of treatment with belimumab IV was $€ 12,448.28$ per patient on ongoing phase (13 administrations per year) and $€ 14,363.40$ per patient on loading phase (15 administrations per year).

Likewise, the annual cost of administration calculated for treatment with belimumab IV was $€ 3388.72$ per patient on ongoing phase and $€ 3910.07$ per patient on loading phase.

Table 2 shows the annual costs per patient associated with flares according to severity and the direct savings associated with flares treated with belimumab. Treatment with belimumab shows an annual reduction in the cost of non-severe and severe flares per patient versus standard therapy of $€ 2444.48$.

\section{Budget Impact Analysis}

The total budget impact of introducing belimumab SC treatment in the Spanish NHS for adult patients with SLE with positive autoantibodies and high disease activity despite standard treatment was calculated as the cost difference between the current scenario and the new scenario. Direct health costs were considered in order to calculate total budget impact: pharmacological treatments, administration, and management of flares. The introduction of 
Table I Estimated Adult Population With SLE With High Disease Activity And Positive Autoantibodies In Spain

\begin{tabular}{|c|c|c|}
\hline & $\mathbf{N}$ & References \\
\hline Spanish adult population & $38,128,226$ & National Institute of Statistics (INE) $2017^{13}$ \\
\hline Population with SLE & 34,697 & EPISER $^{14}$ and systemic auto-immune disease (GEAS) group \\
\hline Diagnosed with SLE & 30,533 & Expert panel ${ }^{15}$ \\
\hline $\begin{array}{l}\text { SLE population without severe active lupus nephritis or severe active } \\
\text { CNS lupus }\end{array}$ & 20,610 & $\begin{array}{l}\text { Adapted from: Somers EC et al } 2009^{16} \text { and Rúa-Figueroa I } \\
\text { et al } 2014^{17}\end{array}$ \\
\hline SLE population with positive autoantibodies and disease activity & 12,220 & Lupus Monitor ${ }^{19}$ \\
\hline SLE population with high disease activity & 4277 & Adapted from Cervera et al $2013^{10}$ \\
\hline On pharmacological treatment & 3849 & Expert panel ${ }^{15}$ \\
\hline
\end{tabular}

Table 2 Annual Costs Per Patient Associated With Flares According To Severity

\begin{tabular}{|l|l|l|}
\hline Treatment & Cost Of Non-Severe Flares & Cost Of Severe Flares \\
\hline Belimumab SC + Standard Therapy & $€ I I 72.4 I$ & $€ 2640.22$ \\
Belimumab IV + Standard Therapy & $€ I I 72.4 I$ & $€ 2640.22$ \\
Standard Therapy & $€ \mid 367.81$ & $€ 4889.30$ \\
Reduction in annual costs & $€ \mid 95.40$ & $€ 2249.08$ \\
\hline Total reduction in annual costs & $€ 2,444.48$ & \\
\hline
\end{tabular}

belimumab SC into the Spanish NHS could generate savings in direct healthcare costs of $€ 6,038,803$ over the 3 years. The results are shown in Figure 1.

Pharmacological budget impact was calculated, considering only pharmacological costs. The introduction of belimumab SC within the Spanish NHS could generate savings of $€ 863,193.20$ over the 3 years. The results of pharmacological budget impact are shown in Table 3. This saving comes from the lower annual treatment cost of belimumab SC compared to belimumab IV on loading or ongoing phase.

\section{Sensitivity Analysis}

The sensitivity analysis confirmed the estimated savings to the Spanish NHS, due to the introduction of belimumab $\mathrm{SC}$ to the pharmacological treatments available for treating adult patients with SLE. This cost saving ranges between 3 and 7 million euros for the total budget impact (Figure 2).

\section{Discussion}

The introduction of belimumab SC shows relevant savings for the Spanish NHS in the 3-year period studied. The results of this study show that direct healthcare costs were lower in patients treated with belimumab SC compared to those treated with belimumab IV. This new subcutaneous formulation will not only reduce the direct costs derived from its administration and acquisition but it will also be able to free-up healthcare facilities mainly in day hospitals, to the benefit of patients and healthcare professionals. In addition, subcutaneous administration is a less invasive treatment than intravenous administration and has a reduced administration time of only a few minutes. It can be a self-administered treatment.

Taking into account that belimumab SC is administered as a weekly fixed-dose regimen of $200 \mathrm{mg}$ regardless of patient weight, there will therefore be a predictable budget impact.

The introduction of belimumab SC into the Spanish NHS could, in its first 3 years of commercialization, generate a saving of approximately 800 thousand euros in pharmacological costs, and a total saving of direct health costs of 6 million euros.

SLE is a chronic, serious condition that affects patients of working age. Given that the disease occurs in women with an average age of 38 years, ${ }^{51}$ there are also significant indirect costs associated with SLE. A real clinical practice study conducted in Spain evaluated variables of healthcare resource consumption and absence from work, after 6 months of treatment with IV belimumab in patients with SLE. The patients treated with belimumab IV presented a reduction in the use of healthcare resources directly related to the management of the disease, such as the use of corticosteroids, as well as a substantial reduction in the days of absence from work. ${ }^{52}$ Additionally, the subcutaneous formulation will offer greater comfort and ease of administration, reducing absence from work as the drug may be administered outside the hospital and 


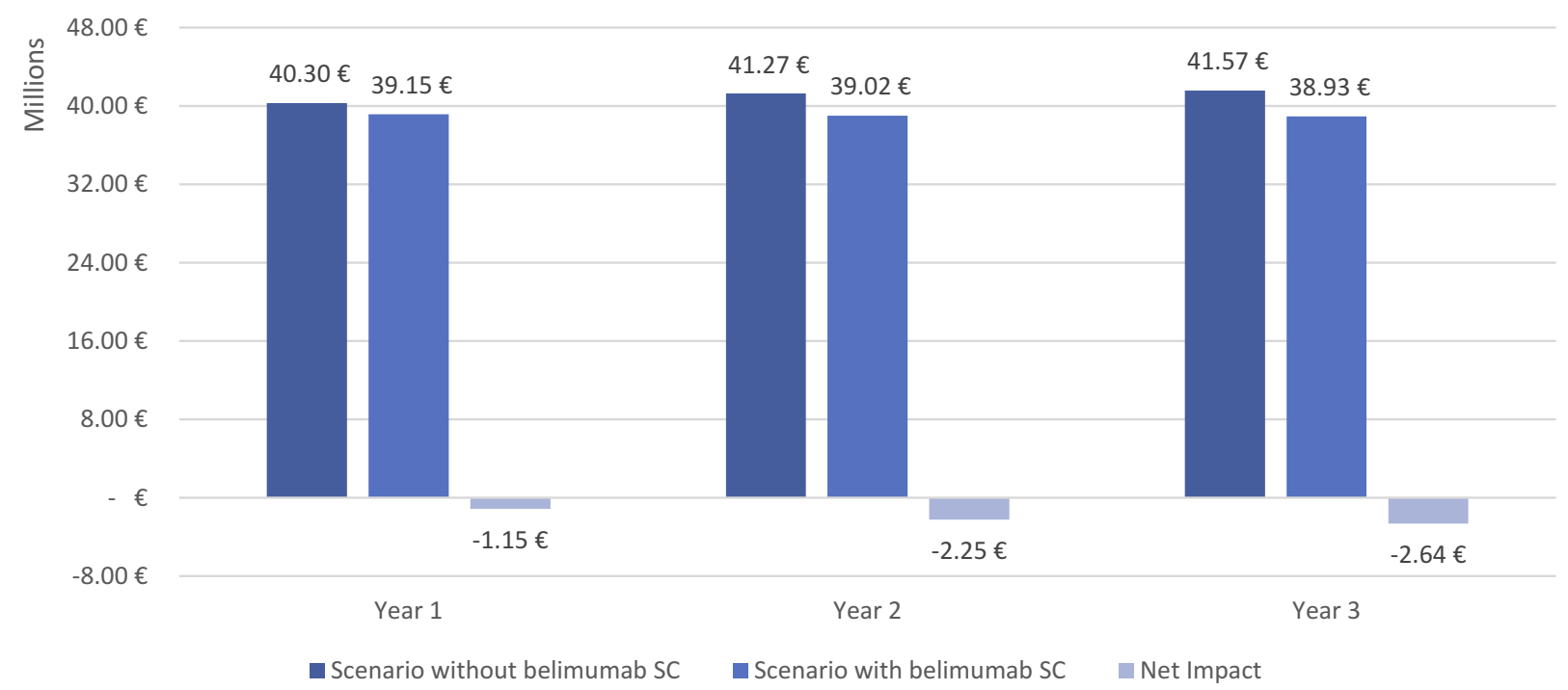

Figure I Total budget impact of the introduction of belimumab SC in the Spanish NHS

even offers an option for patients in whom it is difficult to access veins for injection.

It should also be noted that this disease has associated direct costs derived from clinical management, highlighting the recurrent hospital admissions of patients mainly due to flares and associated organ damage. The LUCIE study showed that the major component of the health cost corresponded to hospital admissions. ${ }^{9}$ Patients treated with belimumab in addition to standard therapy showed a reduced average number of flares per year compared to patients treated with standard therapy alone. ${ }^{42}$

The use of belimumab is recommended in different national clinical guidelines: clinical practice guide on
SLE from the Ministry of Health, Social Services and Equality ${ }^{1}$ clinical practice guide of the Study Group of Autoimmune Diseases (GEAS) of the Spanish Society of Internal Medicine (SEMI) ${ }^{19}$ and the Consensus of the Spanish Society of Rheumatology (SER) on the use of biological therapies in SLE. ${ }^{6}$

To carry out this study and develop the budget impact model, the same efficacy has been set out for both formulations. In a network meta-analysis with the objective of establishing the comparability of both formulations of belimumab IV and SC in patients with SLE, it was demonstrated that in patients with high disease activity, the efficacy of the SC formulation was comparable to that of the IV formulation. ${ }^{53}$

Table 3 Pharmacological Budget Impact Of The Introduction Of Belimumab SC

\begin{tabular}{|c|c|c|c|}
\hline & Year I & Year 2 & Year 3 \\
\hline Total number of patients eligible for belimumab & 3891 & 3943 & 3995 \\
\hline Total patients on belimumab treatment & $889(22.8 \%)$ & $934(23.7 \%)$ & 927 (23.2\%) \\
\hline \multicolumn{4}{|l|}{ Scenario without belimumab SC } \\
\hline Belimumab IV + ST & $€ I I, 002,596.27$ & $€ \mid I, 568,022.00$ & $€ \mid I, 48 I, 887.90$ \\
\hline Standard Therapy & $€ I, 693,285.12$ & $€ I, 7|6,054.3|$ & $€ I, 738,63 I .99$ \\
\hline Total & $€|2,695,88| .38$ & $€|3,284,076.3|$ & $€ \mid 3,220,519.90$ \\
\hline \multicolumn{4}{|l|}{ Scenario with belimumab SC } \\
\hline Belimumab SC + ST & $€ 3,452,758.06$ & $€ 6,763,692.63$ & $€ 7,932,655.42$ \\
\hline Belimumab IV + ST & $€ 7,385,521.46$ & $€ 4,482,603.39$ & $€ 3, \mid 72,082.01$ \\
\hline Standard Therapy & $€ 1,693,285.12$ & $€ I, 7|6,054.3|$ & $€ I, 738,631.99$ \\
\hline Total & $€|2,53|, 564.63$ & $€ \mid 2,962,350.33$ & $€ \mid 2,843,369.43$ \\
\hline Net Impact & $-€|64,3| 6.75$ & $-€ 32 I, 725.98$ & $-€ 377,150.47$ \\
\hline
\end{tabular}

Abbreviation: ST, standard therapy. 


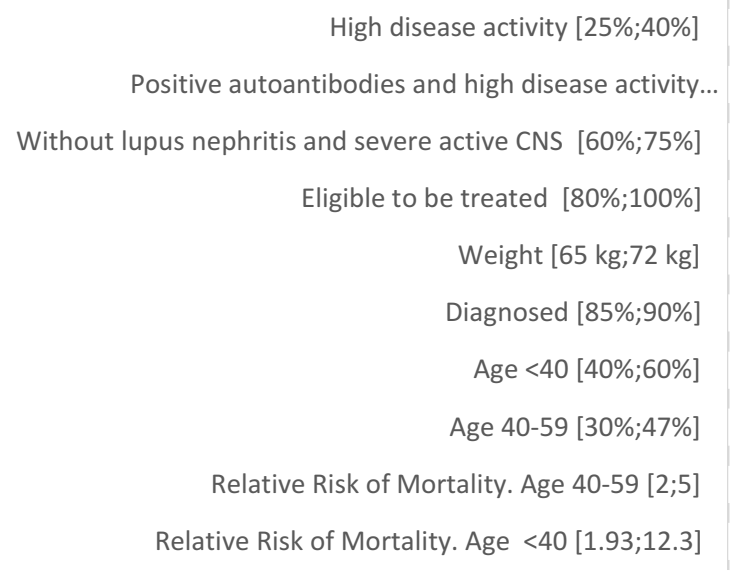

$3.00 €$

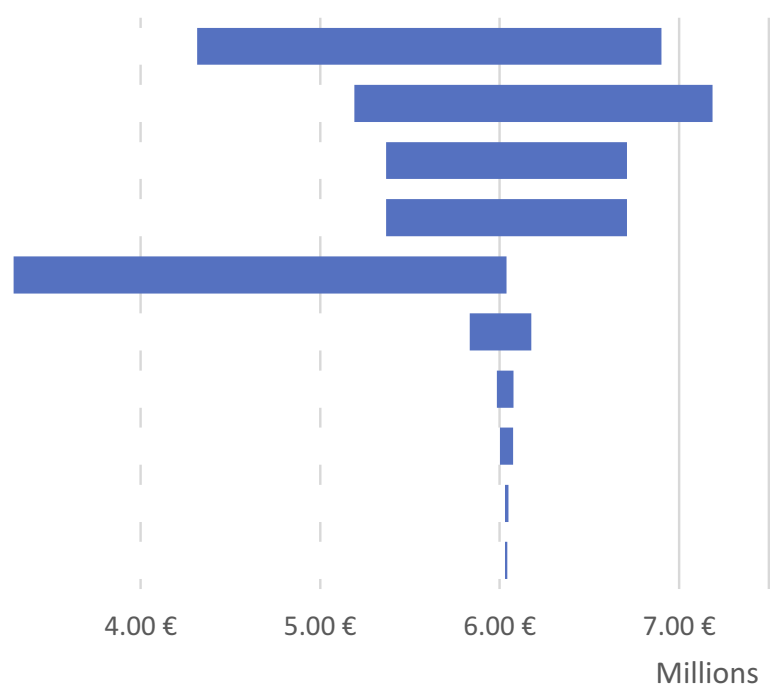

COST-SAVING

Figure 2 Tornado diagram: univariate sensitivity analysis.

This means that both formulations have the same costs in terms of disease management, but with different administration and pharmacological direct costs.

Belimumab has been shown to have a positive effect on the quality of life of patients, both in the physical component and in the vitality domain of the SF-36 and in the fatigue score (FACIT-Fatigue). ${ }^{54}$ These clinically significant improvements are consistent with the reduction of disease activity. Therefore, the use of belimumab in patients with positive autoantibodies and high disease activity despite standard therapy may offer benefits both economically and clinically.

\section{Study Limitations}

Our study is not free from the limitations inherent to estimating the budget impact made using models. However, the information with the most available evidence has been used. Also, the data have been validated by a panel of clinical experts with real experience in the management and treatment of patients with SLE in Spain.

It should be noted that the estimated number of patients being treated who will eventually receive SC belimumab is obviously speculative, and may depend on various aspects, including the low prevalence of the disease, the detection of positive autoantibodies, as well as the clinical criteria and the difficulty in accessing all patients who received treatment. However, the estimated number of patients receiving treatment comes from the EPISER study, ${ }^{13}$ which was conducted more than a decade ago, and the results may be outdated. For this reason, the Spanish Society of Rheumatology has re-launched the study ${ }^{55}$ and, therefore, our results could be affected by the new estimate. In addition, it would be advisable to have longterm epidemiological studies in the future that allow the relevance of SLE to be demonstrated with real data, both at a clinical and economic level, thus better contextualising the consequences of the disease.

\section{Conclusions}

This study provides pharmacoeconomic information that can aid in decision-making related to the prescription of treatments for patients with SLE. The introduction of belimumab SC demonstrates direct savings for the Spanish NHS. This decrease in direct costs will allow a better management of Spanish NHS resources, contributing to its sustainability. This is a study based on estimates and assumptions about future impact. Further developments could be possible to demonstrate the real impact in a retrospective study.

\section{Acknowledgment}

The original model was developed by Timothy M. Klein, Senior Research Analyst, Modelling \& Computer Science, Medical Decision Modelling Inc.

\section{Disclosure}

This study was funded by GlaxoSmithKline (Study code: HO17-18309). M Cevey is an employee of GlaxoSmithKline. Jaime Calvo, Carlos Crespo, Angel Robles, Lee Smolen and Josefina Cortés received consulting fees from GlaxoSmithKline during their participation in the study. Dr. 
Crespo Palomo reports personal fees from GlaxoSmithKline, during the conduct of the study; grants and personal fees from advising outside the submitted work; and he received grants or personal fees from Novartis, Pfizer, Abbvie, Gebro, Takeda, Shire, Mundipharma, Almirall, Boston Scientific, Dexcom, Hospital Clinic of Barcelona, Ferrer, Daichi, Boehringer, Gilead, IESE, Sanofi, Roche, Roche diagnostic, Vifor, EuroQoL, Angellini and Medtronic. Lee J Smolen over the course of the past 36 months Medical Decision Modeling has received financial remuneration from GlaxoSmithKline plc (GSK) for consultant services related to pharmacoeconomic investigations regarding the use of belimumab in the treatment of system lupus erythematosus (SLE). The authors report no other conflicts of interest in this work.

\section{References}

1. Working group of the Clinical Practice Guideline on Systemic Lupus Erythematosus. Clinical practice guideline on systemic lupus erythematosus. Clinical Practice Guidelines in the Spanish NHS. Ministry of Health, Social Services and Equality Evaluation Service of the Canary Islands Health Service; 2015

2. Pons-Estel GJ, Ugarte-Gil MF, Alarcón GS. Epidemiology of systemic lupus erythematosus. Expert Rev Clin Immunol. 2017;13 (8):799-814. doi:10.1080/1744666X2017.1327352

3. Trujillo-Martín MM, Rúa-figueroa Fernández de Larrinoa I, RuízIrastorza G, et al. Clinical practice guidelines for systemic lupus erythematosus: recommendations for general clinical management. Med Clin (Barc). 2016;146(9):413.e1-413.e14. doi:10.1016/j.medcli.2016.01.013

4. Chaigne B, Chizzolini C, Perneger T, et al. Impact of disease activity on health-related quality of life in systemic lupus erythematosus - a crosssectional analysis of the Swiss Systemic Lupus Erythematosus Cohort Study (SSCS). BMC Immunol. 2017;18:17. doi:10.1186/s12865-017-0200-5

5. Albrecht K, Huscher D, Richter J, et al. Changes in referral, treatment and outcomes in patients with systemic lupus erythematosus in Germany in the 1990s and the 2000s. Lupus Sci Med. 2014;1(1): e000059. doi:10.1136/lupus-2014-000059

6. Rodríguez Almaraz ME, Cámara Fernández I, Pablos Álvarez JL. Disseminated Lupus Erythematosus evaluation of the disease. Treatment management of complications. Med - Continued Accredited Medical Form Program. 2017;12(25):1440-1447. doi:10.1016/j.med.2017.01.002

7. Calvo-Alén J, Silva-Fernández L, Úcar-angle E, et al. Consensus of the Spanish Society of Rheumatology on the use of biological therapies in systemic lupus erythematosus. Reumatol Clin. 2013;9(5):281-296.

8. Ramos-Casals M, Ruiz-Irastorza G, Jimenez-Alonso J, Khamashta MA. Recommendations on the use of belimumab in systemic lupus erythematosus. Clinical Practice Guide GEAS-SEMI. Rev Clin Esp. 2013;213(1):42-58. doi:10.1016/j.rce.2012.10.004

9. Doria A, Amoura Z, Cervera R, et al. Annual direct medical cost of active systemic lupus erythematosus in five European countries. Ann Rheum Dis. 2014;73(1):154-160. doi:10.1136/annrheumdis-2012-202443

10. Cervera R, Rúa-Figueroa I, Gil-Aguado A, et al. Direct cost of management and treatment of active systemic lupus erythematosus and its outbreaks in Spain: the LUCIE Study. Rev Clin Esp. 2013;213 (3):127-137. doi:10.1016/j.rce.2012.11.018

11. Zink A, Fischer-Betz R, Thiele K, et al. Health care and burden of disease in systemic lupus erythematosus compared to rheumatoid arthritis: results from the National Database of the German Collaborative Arthritis Centers. Lupus. 2004;13(7):529-536. doi:10.1191/0961203304lu1054oa
12. Sullivan SD, Mauskopf JA, Augustovski F, et al. Budget impact analysis-principles of good practice: report of the ISPOR 2012 Budget Impact Analysis Good Practice II Task Force. Value Health. 2014;17(1):5-14. doi:10.1016/j.jval.2013.08.2291

13. INE. Resident population by date, sex and age. National results. Inst Nac Statistics. 2017

14. Spanish Society of Rheumatology. Episer studio. Available from: http://www.ser.es/episer/. Accessed October 25, 2019.

15. Cevey M, Calvo-Alén J, Crespo C, Robles-Marhuenda A, Cortés J. Systemic lupus erythematosus in Spain in patients with high activity of the disease in the next 5 years. Reumatol Clin. 2018;14(Spec Cong):28-286.

16. Somers EC, Marder W, Lewis EE, et al. Michigan Lupus Epidemiology \& Surveillance Program (MILES): increased proportion of target-organ threatening involvement among male versus female SLE patients. In: American College of Rheumatology $A C R$ ARP Annual Meeting. Philadelphia (PA); 2009:235 [Abstract \# 302].

17. Rúa-Figueroa Í, Richi P, López-Longo FJ, et al. Comprehensive description of clinical characteristics of a large systemic lupus erythematosus cohort from the spanish rheumatology society lupus registry (RELESSER) with emphasis on complete versus incomplete lupus differences. Med (United States). 2015;94(1):e267. doi:10.1097/MD.0000000000000267

18. Summary Product of Characteristics of Benlysta (belimumab) subcutaneous. GlaxoSmithKline. 2018. Available from: https://cima.aemps.es/ cima/pdfs/en/ft/111700004/FT_111700004.pdf. Accessed October 25, 2019.

19. Ipsos Healthcare. Lupus Monitor market research 2016. Madrid 2017

20. Study Group of Systemic Autoimmune Diseases (GEAS). Spanish Society of Internal Medicine (SEMI). Clinical Guidelines of Systemic Autoimmune Diseases. Disseminated Lupus Erythematosus. 2011. Available from: https://www.fesemi.org/sites/ default/files/documentos/publicaciones/guia_les_2011.pdf. Accessed November 08, 2019.

21. National Statistics Institute. Mortality tables by year, sex, age and functions. Results by Autonomous Communities and Provinces. Inst Nac Statistics. 2016. Available from: https://www.ine.es/. Accessed November 27, 2019.

22. Bultink I, de Vries F, van Vollenhoven R, Lalmohamed A. A populationbased study on mortality and the influence of medication use in 4356 patients with systemic lupus erythematosus and 21845 matched controls from the United Kingdom. Lupus Sci Med. 2018;5(Suppl 1):S6A: 4.

23. Bernatsky S, Boivin JF, Joseph L, et al. Mortality in systemic lupus erythematosus. Arthritis Rheum. 2006;54(8):2550-2557. doi:10.1002/art.21955

24. Rúa-Figueroa I, López-Longo FJ, Calvo-Alén J, et al. National registry of patients with systemic lupus erythematosus of the Spanish Society of Rheumatology: objectives and methodology. Clinical Reumatol. 2014;10(1):17-24. doi:10.1016/j.reuma.2013.04.013

25. Consejo General de Colegios Oficiales. Database of Medicine. Bot Plus. 2017

26. Summary Product of Characteristics of Benlysta (belimumab) for solution for infusion. GlaxoSmithKline. 2018. Available from: https://cima.aemps. es/cima/dochtml/ft/11700001/FT_11700001.html. Accessed October 25, 2019.

27. Stohl W, Schwarting A, Okada M, et al. Efficacy and safety of subcutaneous belimumab in systemic Lupus Erythematosus: a fifty-two-week randomized, double-blind, placebo-controlled study. Arthritis Rheum (Hoboken, NJ). 2017;69(5):1016-1027. doi:10.1002/art.40049

28. AEMPS. Technical Sheet Subcutaneous Benlysta. Madrid; 2018. Available from: https://cima.aemps.es/cima/pdfs/en/ft/111700004/ FT_111700004.pdf. Accessed October 25, 2019.

29. National Institute of Statistics European Survey of Health in Spain National results. Madrid 2017

30. Official Gazette of Aragon ORDER of September 17, 2015, of the Directors of the Treasury and Public Administration and of Health, by which the Public Prices for the Provision of Services or Realization of Own Activities of the Aragonese Public Bank Entity are Created. Saragossa; 2015 
31. Official Gazette of Cantabria Approval of the Price Tariff of the Products and Services Provided by the Blood and Tissue Bank of Cantabria for the Year 2017 in the Autonomous Region of Cantabria. Santander; 2017

32. Banc de sang i teixits de Catalunya. Llista de Preus. Barcelona; 2018

33. Official Bulletin of the Canary Islands. Resolution of March 29, 2017, of the Director, by which the Amount of the Public Prices of Sanitary Services Provided is Modified in Decree 81/2009, of June 16, Whereby the Public Prices of Health Services are Established P. 2017

34. Official Gazette of Aragon RESOLUTION of July 30, 2012, of the Management of the Aragonese Health Service, on Revision of the Fees to be Applied for the Provision of Sanitary Services to Third Parties Obligatory to the Payment or to Users Without Right to Sanitary Assistance in L. Zaragoza; 2012.

35. Official Gazette of the Region of Murcia Ministry of Finance and Public Administration. Order of February 16, 2017 Number 48. Murcia; 2017

36. OSAKIDETZA (Basque Health Service) Rates for Invoicing of Sanitary Services and Teachers of Osakidetza for the Year 2018. Vitoria; 2018

37. Official Gazette of La Rioja Resolution Number 169, of January 26, 2012, of the Minister of Health and Social Services for which the Publication of the Rates for Health Services Provided to Individuals is Provided in the Centers of the Riojan Health Service. Logroño; 2012.

38. Official Diari of the Generalitat de Catalunya. SLT/30/2013, of February 20, Whereby the Public Prices of the Catalan Health Service are Approved. Barcelona 2013.

39. Official Bulletin of Madrid. ORDER 727/2017, of August 7, of the Minister of Health, by which the Public Prices for the Provision of the Services and Activities of Sanitary Nature of the Network of Centers of the Community of Madrid are Fixed. Madrid 2017

40. Official Gazette of the Council of Andalusia ORDER of October 14, 2005 Whereby the Public Prices of Health Services Provided by Dependent Centers of the Public Health System of Andalusia. Sevilla, 2005.

41. Parks D, Ramachandran S, Kurtinecz M, Asukai Y, Alfonso-Cristancho $\mathrm{R}$. Indirect comparative clinical effectiveness of intravenous and subcutaneous formulations of Benlysta for the treatment of adult patients with active, autoantibody-positive systemic lupus erythematosus with high disease activity. Ann Rheum Dis. 2017;76(Suppl 2).

42. Cevey M, Calvo-Alén J, Crespo C, Robles-Marhuenda A, Cortés J Direct cost offsets related to belimumab subcutaneous administration in patients with systemic lupus erythematosus in Spain. Available from: https://tools.ispor.org/ScientificPresentationsDatabase/ Presentation $/ 85326$ ?pdfid=56520. Accessed October 25, 2019.

43. Ministry of Health, Social Services and Equality Institute of Health Information. Registration of registrations - CMBD 2015. MSSSI 2017. Available from: https://www.msssi.gob.es/estadEstudios/estadisticas/ sisInfSanSNS/aplicacionesConsulta/home.htm. Accessed November 2017

44. Boletín Oficial de Canarias. Resolución de 29 de Marzo de 2017, Del Director, Por La Que Se Modifica La Cuantía de Los Precios Públicos de Servicios Sanitarios Previstos En El Decreto 81/2009, de 16 de Junio, Por El Que Se Establecen Los Precios Públicos de Los Servicios Sanitarios P.; 2017.
45. Boletín oficial de Aragón. Resolución de 30 de Julio de 2012, de La Dirección Gerencia Del Servicio Aragonés de Salud, Sobre Revisión de Las Tarifas a Aplicar Por La Prestación de Servicios Sanitarios a Terceros Obligados Al Pago o a Usuarios Sin Derecho a Asistencia Sanitaria En L. Zaragoza; 2012.

46. Osakidetza. Tarifas Para Facturación de Servicios Sanitarios y Docentes de Osakidetza Para El Año 2018. Vitoria; 2018.

47. Boletín oficial de La Rioja. Resolución Número 169, de 26 de Enero de 2012, Del Consejero de Salud y Servicios Sociales Por La Que Se Dispone La Publicación de Las Tarifas Por Servicios Sanitarios Prestados a Particulares En Los Centros Del Servicio Riojano de Salud. Logroño; 2012.

48. Diari Oicial de la Generalitat de Catalunya. SLT/30/2013, de 20 de Febrero, Por La Que Se Aprueban Los Precios Públicos Del Servicio Catalán de La Salud. Barcelona; 2013.

49. Boletín oficial de Madrid. Orden 727/2017, de 7 de Agosto, Del Consejero de Sanidad, Por La Que Se Fijan Los Precios Públicos Por La Prestación de Los Servicios y Actividades de Naturaleza Sanitaria de La Red de Centros de La Comunidad de Madrid. Madrid; 2017.

50. Boletín Oficial de la Junta de Andalucía. Orden de 14 de Octubre de 2005, Por La Que Se Fijan Los Precios P-blicos de Los Servicios Sanitarios Prestados Por Centros Dependientes Del Sistema Sanitario Público de Andalucía. Sevilla; 2005.

51. Stohl W, Schwarting A, Okada M, et al. Efficacy and safety of subcutaneous Benlysta in systemic lupus erythematosus: a randomized, double-blind, placebo-controlled, 52-week study. Arthritis Rheum. 2017. doi:10.1002/art.40049

52. Cortés J, Andreu JL, Calvo J, et al. Evaluation of use of benlysta in clinical practice settings (Observe Study) in Spain: health resource utilization and labor absenteeism. Value Health. 2014;17(7):A534. doi:10.1016/j.jval.2014.08.1703

53. Parks D, Ramachandran S, Kurtinecz M, Asukai Y, AlfonsoCristancho R. SAT0223 indirect comparative clinical effectiveness of intravenous and subcutaneous formulations of belimumab for the treatment of adult patients with active, autoantibody-positive systemic lupus erythematosus with high disease activity. In: EULAR Congress. Poster Presentations. BMJ Publishing Group Ltd and European League Against Rheumatism; 2017:857.3-858. doi:10.1136/annrheumdis-2017-eular.4701

54. Strand V, Levy RA, Cervera R, et al. Improvements in health-related quality of life with belimumab, a B-lymphocyte stimulator-specific inhibitor, in patients with autoantibody-positive systemic lupus erythematosus from the randomized controlled BLISS trials. Ann Rheum Dis. 2014;73(5):838-844. doi:10.1136/annrheumdis-2012-202865

55. Seoane-Mato D, Sánchez-Piedra C, Silva-Fernández L, et al. Prevalence of rheumatic diseases in the adult population in Spain (EPISER 2016 study). III. Objectives and methodology. Clinical Reumatol. 2017. doi:10.1016/j.reuma.2017.06.009
ClinicoEconomics and Outcomes Research

\section{Publish your work in this journal}

ClinicoEconomics and Outcomes Research is an international, peerreviewed open-access journal focusing on Health Technology Assessment, Pharmacoeconomics and Outcomes Research in the areas of diagnosis, medical devices, and clinical, surgical and pharmacological intervention. The economic impact of health policy and health systems organization also constitute important areas of coverage. The manuscript management system is completely online and includes a very quick and fair peer-review system, which is all easy to use. Visit http://www.dovepress.com/testimonials.php to read real quotes from published authors. 